\title{
Perancangan Hovercraft Pengangkut Sistem Desalinasi Untuk Pelayaran Jarak Dekat AntarPulau
}

\author{
Taufan Prasetyo ${ }^{1}$, Misbakhul Fatah ${ }^{2}$, Ike Dayi Febriana \\ ${ }^{1}$ Jurusan Teknik Bangunan Kapal, Politeknik Negeri Madura \\ 2,3 Jurusan Teknik Mesin Alat Berat, Politeknik Negeri Madura \\ Kampus A Politeknik Negeri Madura, Sampang 69281 \\ taufanprasetyo@poltera.ac.id
}

\begin{abstract}
Abstrak
Pulau-pulau kecil di Indonesia dengan kriteria luas yang kurang dari 2.000 $\mathrm{m}^{2}$ tidak memiliki sumber air bersih yang cukup. Banyak solusi yang sudah dikembangkan terkait krisis air bersih ini salah satunya menyediakan alat penyulingan air laut menjadi air bersih atau biasa disebut sistem desalinasi. Namun itu tidak berjalan efektif dikarenakan biaya perawatan alat yang mahal dan iuran yang tidak sebanding dengan pendapatan penduduk sekitar. Pada penelitian ini dirancang suatu transportasi air yang mampu mendistribusikan mesin atau sistem desalinasi portabel beserta kebutuhan logistik lainnya dari pulau ke pulau. Dikarenakan tidak semua pulau memiliki dermaga dan fasilitas bongkar muat yang memadai, maka peneliti berinisiatif untuk merancang sebuah Kapal Amphibi berjenis Hovercraft untuk mempermudah proses distribusi hingga bongkar muat di daratan. Proses perancangan dilakukan menggunakan metode sister ship dengan mempertimbangkan ukuran benda yang akan diangkut sehingga ditentukan Panjang $=13,2 \mathrm{~m}$, Lebar $=6,7 \mathrm{~m}$, material Aluminium, dengan total berat $=19$ ton, Kecepatan $=50$ knot, dan desain mengacu pada Hovercraft tipe pengangkut. Berdasarkan data-data tersebut didapatkan kapasitas total daya angkat sebesar 1909,44 HP dan daya dorong sebesar 695, $61 \mathrm{HP}$.
\end{abstract}

Kata kunci: Hovercraft, Kapal Amphibi, Daya Angkat, Daya Dorong

\section{Abstract}

Small islands in Indonesia with an area of less than $2.000 \mathrm{~m}^{2}$ do not have sufficient clean water sources. Many solutions have been developed regarding the clean water crisis, which one is to provide a distilling seawater into clean water or what the local government calls the desalination system. However, it did not work effectively because the cost of equipments maintenance was quite expensive. In this study, a water transportation for 
distributing portable desalination machines between island is designed. Due to the lack of adequate docks and loading facilities on many islands, the researchers took the initiative todesign a Hovercraft, an Amphibious Ship to simplify the distribution and loading process on land. The design process is carried out using the sister ship method by considering the size of the object to be distributed so that the length $=13.2 \mathrm{~m}$, Width $=6.7 \mathrm{~m}$, Aluminum material, with a total weight $=19$ tons, Speed $=50 \mathrm{knots}$, and the design refers to the Carrier type of Hovercraft. Based on these data, the total lifting capacity is 1909.44 HP and the thrust is 695.61 HP.

Keywords: Hovercraft, Amphibi, Lift Capacity, Thrust Capacity 


\section{PENDAHULUAN}

Indonesia merupakan salah satu negara kepulauan yang terdiri dari beberapa pulau besar dan beribu-ribu pulau kecil. Menurut data terbaru, total sebanyak 17.504 pulau ada di perairan Indonesia dengan 6.000 di antaranya merupakan pulau berpenghuni. Dengan kondisi geografis di Indonesia yang memiliki banyak pulau-pulau dan dikellingi oleh laut yang hampir sepertiga bagian dari negara ini, kapal dan kendaraan air lainnya merupakan alat transportasi utama yang digunakan, baik untuk mengangkut penumpang maupun barang. Terdapat berbagai jenis dan ukuran kapal yang beroperasi di Indonesia bergantung pada fungsi dan kapasitas muatan yang diangkut. Kapalkapal besar sangat berguna untuk mengangkut muatan dengan kapasitas yang sangat besar dan dengan jarak pelayaran yang cukup jauh namun kurang efektif apabila digunakan pada pelayaran jarak dekat. Sedangkankapalkapal kecil cukup efektif digunakan pada pelayaran jarak dekat dan pelayaran antar pulau-pulau kecil.

Salah satu permasalahan lain dari negara kepulauan seperti yang di Indonesia ini adalah ketersediaan air bersih terutamanya di pulau-pulau kecil. Definisi pulau kecil itu sendiri adalah pulau yang memiliki luasan kurang dari 2.000 meter persegi. Tidak sepertipulaupulau besar seperti Pulau Jawa, Sumatera, Kalimantan, dan lain-lain, pulau-pulau kecil tidak memiliki sumber air bersih yang cukup atau bahkan tidak ada sama sekali. Biasanya, penduduk yang mendiami pulau tersebut memanfaatkan air hujan untuk kebutuhan sehari-hari. Mereka mengumpulkan dan menyimpan air pada saat musim hujan dan menghematnya dengan cara melakukan aktifitas mandi dan mencuci menggunakan air laut kemudian menggunakan air hujan untuk membilasnya saja.. Banyak solusi yang sudah dikembangkan terkait krisis air bersih ini salah satunya menyediakan alat penyulingan air laut menjadi air bersih oleh pemerintah setempat. Namunitu tidak berjalan efektif dikarenakan biaya perawatan alat tersebut cukup mahal dan iuran yang dibebankan pada masyarakat untuk biaya perawatan tidak sebanding dengan pendapatan penduduk sekitar.

Di samping itu, tidak semua pulau-pulau kecil tersebut memiliki dermaga dan fasilitas bongkar muat yang layak. Oleh karena itu pada penelitian ini, peneliti bermaksud mengembangkan sebuah kapal berjenis Hovercraft yang merupakan kapal amfibi yang digunakan sebagai alat pengangkut sistem desalinasi portabel untuk membantu ketersediaan air bersih di beberapa pulau di Indonesia pada pelayaran jarak dekat. Jenis Hovercraft dipilih karena kemampuannya yang bisa beroperasi di darat sehingga memungkinkan untuk naik ke darat melalui pantai sehingga ketiadaan dermaga tidak akan menjadi halangan.

\section{METODOLOGI}

Pada proses perancangan Hovercraft ini,peneliti menggunakan metode Sister Ship dan terdapat beberapa tahapan, antara lain:

\subsection{Studi Literatur}

Studi literatur yang dilakukan yaitu mencari permasalahan yang ada pada bidang kemaritiman terutama 


\section{kecil \\ pada pemanfaatan kapal-kapal \\ 2.2. Perumusan Masalah \\ Perumusan masalah yang diangkat padapenelitian ini meliputi:}

- Bagaimana desain hovercraft pengangkut sistem desalinasi yang sesuai untuk pelayaran jarak dekat?

- Berapa daya mesin yang digunakan pada hovercraft pengangkut sistem desalinasi untuk pelayaran jarak dekat?

\subsection{Pengumpulan data}

Data yang diperlukan adalah data kapasitas alat untuk kebutuhan per pulau yang akan dijadikan acuan pencarian sistem desalinasi portabel yang ada di pasaran beserta ukuran dan beratnya.

\subsection{Penentuan Kapasitas Muat Kapal}

Ditentukan kapasitas muat kapal berdasarkan data berat alat desalinasi.

\subsection{Perencanaan Desain Lambung Kapal dan Rencana Umum}

Dari data kapasitas sebelumnya kemudian dijadikan dasar untuk membuat perencanaan desain lambung dan rencana umum.

\subsection{Perencanaan Kapasitas Daya Untuk Sistem Angkat dan Dorong}

Kemudian menghitung kapasitas daya sistem angkat dan dorong berdasarkan bentuk lambung, kapasitas, dan kecepatan yang diinginkan yang mengacu pada buku Theory and Design of Air Cushion Craft oleh L. Yun dan A. Bliault dengan mengikuti beberapa perhitungan berikut:

- Perhitungan Daya Angkat

$\mathrm{FanN}_{1}=\left(\mathrm{H}\right.$. Q) / ( $\left.\eta_{\mathrm{F}} . \eta_{\mathrm{M}}\right)$

$\eta_{\mathrm{F}} \quad=$ Efisiensi Fan $(0,92)$
$\eta_{M}=$ Efisiensi Transmisi $(0,98)$

- Perhitungan Daya Dorong

$\mathrm{N}_{\mathrm{BHP}}=\mathrm{N}_{\mathrm{E}} / \eta_{\mathrm{p}}$

$\eta_{\mathrm{p}}=$ Efisiensi Propeller

$\mathrm{N}_{\mathrm{E}} \quad=\mathrm{R}_{\mathrm{acv}} \cdot \mathrm{v}$

$\mathrm{R}_{\mathrm{acv}}=$ Hambatan Total Hovercraft

$\mathrm{R}_{\mathrm{acv}}=\mathrm{R}_{\mathrm{w}}+\mathrm{R}_{\mathrm{a}}+\mathrm{R}_{\mathrm{m}}+\mathrm{R}_{\mathrm{sk}}+\mathrm{R}_{\mathrm{a}}$ " $\mathrm{R}_{\mathrm{w}}$

= Wave Making Resistance

$\mathrm{R}_{\mathrm{a}} \quad=$ Aerodynamic Profile Resistance

$\mathrm{R}_{\mathrm{m}} \quad=$ Momentum Resistance

$\mathrm{R}_{\mathrm{sk}}=$ Skirt Resistance

$\mathrm{R}_{\mathrm{a}}, \quad=$ Differential Air Momentum

\section{Resistance}

\subsection{Analisa Pembahasan}

Analisa dilakukan untuk mencari nilai efisiensi daya motor untuk lift dan thrust terhadap bentuk dan kapasitas kapal. Sedangkan kapasitas kapal itu sendiri diperoleh berdasarkan kapasitas daya angkut yang diinginkan yang mengacu pada tabel yang ada pada buku Theory and Design of Air Cushion Craft.

\subsection{Kesimpulan}

\section{HASIL DAN PEMBAHASAN}

Berdasarkan hasil pencarian, ditemukan kapasitas sistem Desalinasi Portabel berbasis SWRO (Sea Water Reverse Osmosis) dengan kapasitas terbesar 20.000 liter/jam dengan berat alat $=1,5$ ton.

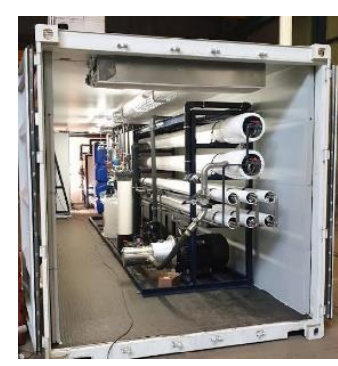

Gambar 1 Sea

Water Reverse

Osmosis

berkapasitas

20.000 Liter/jam

(Sumber : PT

Fratech Rekatirta

Andalan) 
Berdasarkan kapasitas sistem desalinasi, ditentukan ukuran Hovercraft dengan menggunakan metode Sister Shipyang mengacu pada table yang ada di Buku Theory and Design of Air Cushion Craft yang ditulis oleh L. Yun dan A. Bliault dengan ukuran sebagai berikut

- $\mathrm{L}=13,2 \mathrm{~m}$

- $\mathrm{B}=6,7$

- $\mathrm{W}($ Berat Total $)=14,7$ ton

- $\mathrm{L} / \mathrm{B}=1,97$ (untuk Hovercraft, nilaiL/B $\max =3$ )

- $\mathrm{B}_{\mathrm{c}}=6,07$

- $\mathrm{L}_{\mathrm{c}}=12,57$

- $\mathrm{P}_{\mathrm{c}}$ (Tekanan pada Bantalan $)=193$ $\mathrm{Kg} / \mathrm{m}^{2} \rightarrow 1893,33 \mathrm{~N} / \mathrm{m}^{2}$ dikalikan gravitasi

- $\mathrm{S}_{\mathrm{c}}$ (Luas Bantalan $)=76,3 \mathrm{~m}^{2}$

- $\mathrm{V}=50 \mathrm{knot} \rightarrow 25,72 \mathrm{~m} / \mathrm{s}$

- Material Aluminium, karena berat di atas 3 ton

\subsection{Perencanaan}

\section{DesainHovercraft}

Desain mengacu pada bentuk Hovercraft tipe pengangkut yang pernah dibangun didalam negeri yaitu Kartika Hovercraft milik TNI

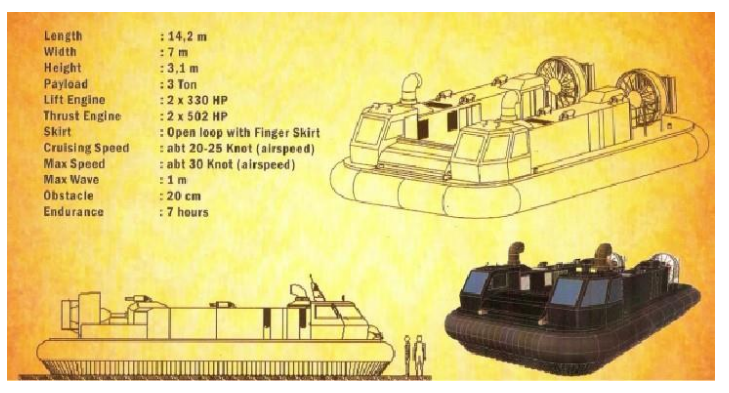

Gambar 2 Kartika Hovercraft

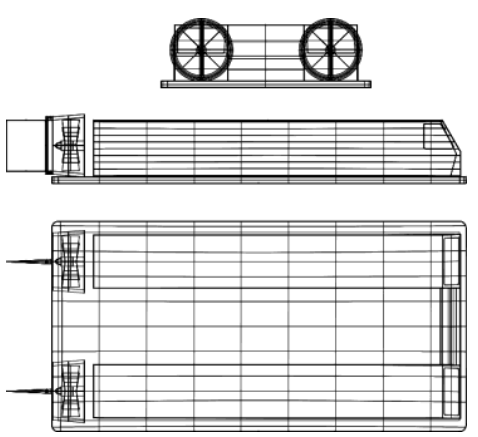

Gambar 3 Desain Linesplan Hovercraft

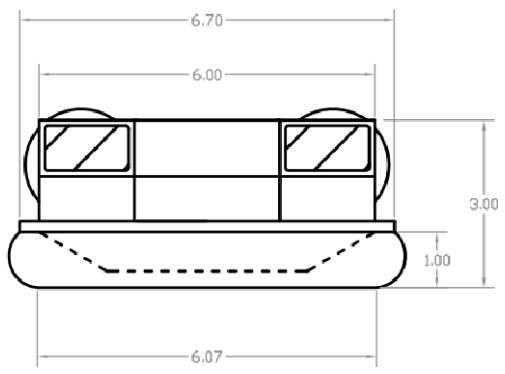

Gambar 4 Desain Tampak Depan

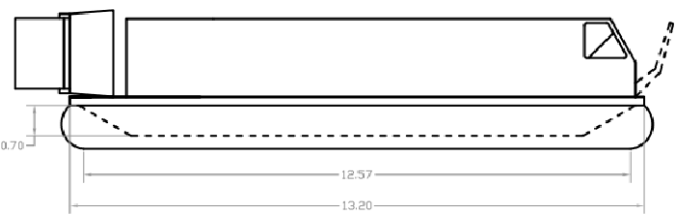

Gambar 5 Desain Tampak Samping

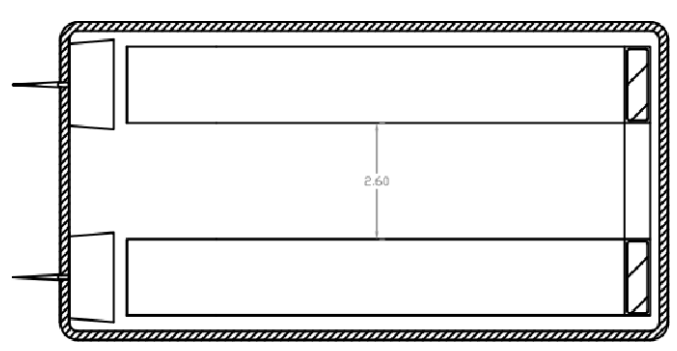

Gambar 6 Desain Tampak Atas 


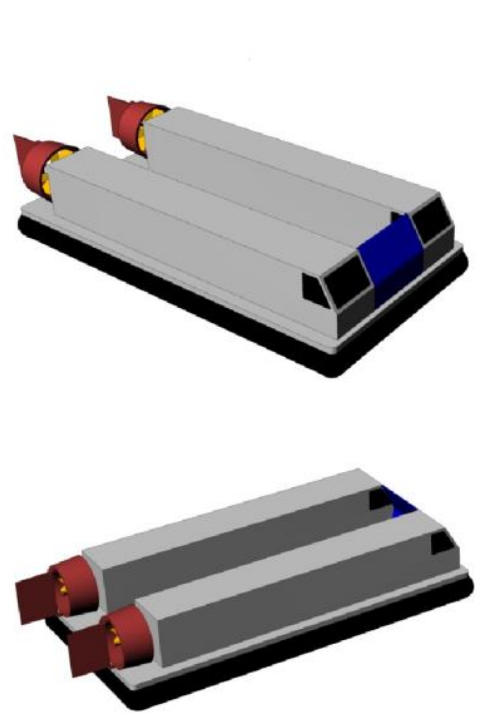

Gambar 7 Desain 3D Hovercraft

\subsection{Besar Lift Capacity}

- Besar Kebutuhan Flow Rate

$(\mathrm{Q}) \mathrm{Q}=\mathrm{Q}^{\prime} \cdot \mathrm{S}_{\mathrm{c}} \cdot\left(2 \cdot \mathrm{P}_{\mathrm{c}} / \rho_{\mathrm{a}}\right)^{0,5}$

$Q^{\prime}=0,015$

$\mathrm{Q}=63,61 \mathrm{~m}^{3} / \mathrm{s}$

- Besar Tekanan Total Fan

(H) $\mathrm{H}=\mathrm{H}^{\prime} \cdot \rho_{\mathrm{a}} \cdot \mathrm{u}_{2}{ }^{2}$

$\mathrm{H}^{\prime}=\left(\mathrm{Q}^{0,5} / \mathrm{N}_{\mathrm{s}}\right)^{4 / 3}$

$\mathrm{N}_{\mathrm{s}}=4$ (Axial Fan)

$\mathrm{u}_{2}=81 \mathrm{~m} / \mathrm{s}$ (circular velocity of impeller)

$\mathrm{H}=20181,704 \mathrm{~N} / \mathrm{m}^{2}$

- Besar Daya Angkat Fan

$\mathrm{N}_{1}=1909,44 \mathrm{HP}$

\subsection{Besar Thrust Capacity}

- Besar Wave Making Resistance $\left(R_{w}\right)$

$$
R_{\mathrm{w}}=C_{\mathrm{w}}\left[\frac{p_{\mathrm{c}}^{2} \cdot B_{\mathrm{c}}}{\left(\rho_{\mathrm{w}} \cdot g\right)}\right]
$$

$\rho_{\mathrm{w}}($ massa jenis air laut $)=1025 \mathrm{~kg} / \mathrm{m}^{3}$

$$
\mathrm{L}_{\mathrm{c}} / \mathrm{B}_{\mathrm{c}}=2,1
$$

Froud Number $\left(\mathrm{Fr}_{1}\right)$

$$
\mathrm{Fr}_{1}=\mathrm{V} /\left(\mathrm{g} \cdot \mathrm{L}_{\mathrm{c}}\right)^{0,5} \mathrm{Fr}_{1}=2,317
$$

Nilai FP dan L/B digunakan dalam pembacaan Diagram untuk mencari nilai $\mathrm{C}_{\mathrm{w}}$

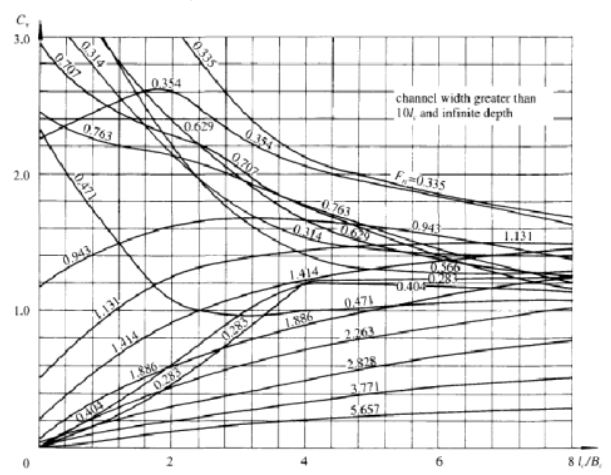

\section{Gambar 8 C $C_{w}$ Diagram}

$\mathrm{R}_{\mathrm{w}} \quad=1082,348 \mathrm{~N}$

- Besar Aerodynamic Profile Resistance $\left(R_{a}\right)$

$$
R_{\mathrm{a}}=C_{\mathrm{a}} \frac{\rho_{\mathrm{a}}}{2} \cdot S_{\mathrm{a}} v^{2}
$$

$\mathrm{C}_{\mathrm{a}}=0,5$

Nilai $S_{a}$ mengacu pada gambar penampang melintang desain Hovercraft

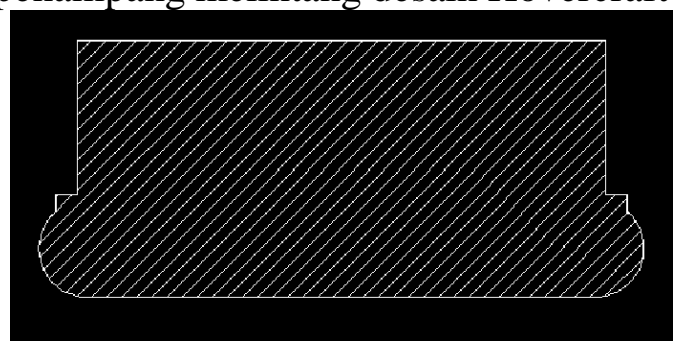

Gambar 9 Luas Penampang Melintang

$\mathrm{R}_{\mathrm{a}}=3932,492 \mathrm{~N}$

- Besar Momentum Resistance $\left(R_{m}\right)$

$$
R_{\mathrm{m}}=Q \rho_{\mathrm{a}} v
$$


$\mathrm{R}_{\mathrm{m}} \quad=2005,306 \mathrm{~N}$

- Perhitungan Skirt Resistance $\left(R_{s k}\right)$

$$
\begin{aligned}
& R_{\mathrm{sk} 1}=C_{\mathrm{sk} 1} \times 10^{-6}\left(h / l_{\mathrm{j}}\right)^{-0.34} l_{\mathrm{j}} S_{\mathrm{c}}^{0.5} q_{\mathrm{w}} \\
& R_{\text {sk2 }}=C_{\mathrm{sk} 2} R_{\mathrm{w}} \\
& C_{\text {sk2 } 2}=\left\{\left[2.8167\left(p_{\mathrm{c}} / l_{\mathrm{c}}\right)^{-0.259}\right]-1\right\} \\
& \mathrm{C}_{\mathrm{sk} 1}=3,5 \\
& \mathrm{~h} \quad=0,3 \\
& \mathrm{l}_{\mathrm{j}}=2 \times\left(\mathrm{L}_{\mathrm{c}}+\mathrm{B}_{\mathrm{c}}\right) \\
&=37,28 \mathrm{~m} \\
& \mathrm{q}_{\mathrm{w}} \quad 0,5 \cdot \rho_{\mathrm{w}} \cdot \mathrm{v}^{2} \\
&=0,5 \mathrm{x} 1025 \mathrm{x} 25,72^{2} \\
&=339028,18 \\
& \mathrm{R}_{\mathrm{sk} 1}=1991,235 \mathrm{~N} \\
& \mathrm{C}_{\mathrm{sk} 2}= 0,388\left(\mathrm{P}_{\mathrm{c}}\right. \text { untuk pencarian nilai } \\
&\left.\mathrm{C}_{\mathrm{sk} 2} \text { adalah } \mathrm{P}_{\mathrm{c}} \text { dengan satuan } \mathrm{Kg} / \mathrm{m}^{2}\right) \\
& \mathrm{R}_{\mathrm{sk} 2}=419,951 \mathrm{~N} \\
& \mathrm{R}_{\mathrm{sk}}= 2411,186 \mathrm{~N}
\end{aligned}
$$

- Besar Differential Air Momentum Resistance ( $\left.R_{a "}\right)$

$$
R_{a^{*}}=W \tan \psi^{\prime}-R_{\mathrm{w}}
$$

$\mathrm{R}_{\mathrm{a}}=7711,275 \mathrm{~N}$

- Besar Tahanan total

$\mathrm{R}_{\mathrm{acv}}=17142,607 \mathrm{~N}$

- Besar Daya Dorong

$\mathrm{N}_{\mathrm{E}}=591,267 \mathrm{HP} \mathrm{N}_{\mathrm{BHP}}$

$=695,608 \mathrm{HP}$

\section{KESIMPULAN}

Berdasarkan analisa hasil perancangan didapatkan spesifikasi Hovercraft pembawa Sistem desalinasi sebagai berikut

1. Panjang Kapal $(\mathrm{L})=13,2 \mathrm{~m}$ dan Lebar (B) $=6,7$; Berat Total $(\mathrm{W})=14,7$ ton; $\mathrm{V}=50$ knot; Tinggi Skirt

$=1 \mathrm{~m}$; Tipe Bag Skirt; Tinggilambung $=0,7 \mathrm{~m} ; \quad$ Tinggi keseluruhan Hovercraft $=3 \mathrm{~m} ;$ Material Aluminium; Menggunakan

2 Impeller; Tipe Pengangkut; Peripheral Jet Type.

2. Kapasitas Daya Angkat sebesar 1909,44 HP dan Daya Dorong BHP sebesar 695,608 HP.

\section{DAFTAR PUSTAKA}

DY, H., \& S, A. (2011). Perencanaan Sistem Thruster dan Lifter Tipe Terpisah untuk Hovercraft Militer dengan Payload 15 Ton.

Gillmer, T. C., \& Johnson, B. (1982). Introduction to Naval Architecture with revisions edition. Naval Institute Press.

L, Yun., \& A, Bliault. (2000). Theory and Design of Air Cushion Craft.

Rizky W.H., D. (2015). DesainHovercraft 20 Pax Untuk Keperluan Pertambangan Minyakdan Gas di Onshore. Skripsi. Teknik Sistem Perkapalan ITS.

Sentosa HS, D. N., Chrismianto, D., \& Manik, P. (2014, Oktober 4). Studi Perancangan Rescue Hovercraft Untuk Evakuasi Korban Bencana Alam. Jurnal Teknik Perkapalan .

Sv. Aa., H. (1992). Resistance and 
Propulsion of Ships. Krieger Pub Co.

W.P.A, V. L. (1961). Ships and Marine Engines (Vol. 3). Stam: Technical Publishing Company. Zulfi, M.; Farid, A.; Fuhaid, N. (2015). Perancangan dan Pengujian Kendaraan Tipe Integrated Hovercraft. Widya Teknika 